\title{
Cross-language facilitation, semantic blindness, and the relation between language and memory: A reply to Altarriba and Soltano
}

\author{
DONALD G. MACKAY, LISE ABRAMS, MANISSA J. PEDROZA, and MICHELLE D. MILLER \\ University of Califormia, Los Angeles, California
}

\begin{abstract}
This comment corrects some inaccuracies, points to some methodological problems, and makes three substantive observations regarding the Altarriba and Soltano (1996) article. First, token individuation theory does not explain what is new and interesting in the Altarriba and Soltano data, namely cross-language semantic facilitation in lists and a list-sentence effect, that is, a large difference in the effect of semantic repetition when identical translation equivalents occurred in sentences versus lists. Second, Altarriba and Soltano's small and nonsignificant semantic blindness effect for translation equivalents in split-language sentences is attributable to the peculiar nature of their materials, procedures, analyses, and experimental design. These problems nullify their conclusion that semantic blindness does not occur, and we discuss several clear cases where semantic blindness has been demonstrated. Finally, we suggest an explanation for Altarriba and Soltano's unexplained effects (cross-language facilitation and the list-sentence effect) and show why these effects are important for the general issue of relations between language and memory.
\end{abstract}

This commentary doesn't just discuss flaws and inaccuracies in the target article (Altarriba \& Soltano, 1996). It also examines three new and unexplained effects in the Altarriba and Soltano data: cross-language facilitation in lists, a list-sentence difference, and the nonoccurrence of semantic blindness (SB) in the split-language sentences of their Experiment 1B. The commentary then addresses some theoretical and methodological implications of these effects and shows why they are important for anyone interested in the relation between language and memory.

\section{CROSS-LANGUAGE FACILITATION}

Cross-language facilitation is the unexplained new effect that appeared in Altarriba and Soltano (1996, Experiment 2), where the procedure was as follows: Proficient bilinguals immediately recalled rapid serial visual presentation (RSVP) lists consisting critically of three words that were preceded and followed by masking stimuli (symbol strings) that participants were instructed to ignore. If the first and last words in the lists are labeled the "pretarget" and "target," respectively, the dependent variable was recall of the target (e.g., drive) as a function of whether its pretarget was identical (e.g., drive-drive), semantically identical (i.e., a translation equivalent, as in

Support from National Institute for Aging Grant 5 R01 AG 09755 to D.G.M., National Science Foundation Graduate Fellowships to L.A. and M.M., and a National Research Service Award to M.M. is gratefully acknowledged. The authors thank D. Burke for helpful comments on an earlier version of the paper. Correspondence should be addressed to D. G. MacKay, Psychology Department, University of California, Los Angeles, Los Angeles, CA 90095-1563 (e-mail: mackay@) psych.ucla.edu) manejar-drive), or unrelated (e.g., steer-drive, or guiardrive). ${ }^{1}$ The interesting finding was that when the pretarget was a translation equivalent (manejar), participants exhibited a statistically reliable facilitation effect (relative to the unrelated condition) in recalling drive, but exhibited the usual inhibitory effect (known as repetition blindness, or RB) when the pretarget was an exact repetition (drive).

It is important to note that cross-language facilitation poses a problem for token individuation theory, in either its original or newer forms. The original token individuation theory (e.g., Kanwisher, 1987; Kanwisher \& Potter, 1990 ) does not explain semantic facilitation because token individuation was considered a purely visual phenomenon, restricted to the processing of visual forms rather than visual concepts, orthographic concepts, phonological concepts, or semantic concepts. Similarly, the newer token individuation theory (e.g., Bavelier, 1994) does not explain semantic facilitation because, given RB conditions, it predicts that orthographic, phonologic, or lexical repetition will lead to inhibition, but not facilitation.

Moreover, cross-language facilitation also presents problems for "multistore" memory theories that postulate phonological, articulatory, or acoustic representations for short-term memory (see, e.g., Gathercole \& Baddeley, 1993, pp. 8-17; Shiffrin \& Nosofsky, 1994; Zhang \& Simon, 1985), but not semantic representations. Like MacKay and Miller's (1994) SB phenomenon (i.e., reliably reduced target recall when pretargets are semantically identical vs. different from the target), Altarriba and Soltano's (1996) cross-language facilitation effect indicates that short-term memory includes semantic representations in addition to phonological, articulatory, or acoustic representations. 


\section{THE LIST-SENTENCE EFFECT}

The list-sentence effect refers to the large difference in the effect of semantic repetition that Altarriba and Soltano (1996) found when they embedded identical translation equivalents in sentences (Experiment 1B) versus lists (Experiment 2). That is, Altarriba and Soltano observed $13 \%$ facilitation in recall (relative to the unrelated condition) for translation equivalents in lists, but observed 3\% inhibition or reduced recall (relative to the unrelated condition) when the same translation equivalents (e.g., drive-manejar) occurred in split-language sentences such as, "Mike learned to drive and empesó a manejar al trabajo" (translation: "Mike learned to drive and began to drive to work."). Like their significant cross-language facilitation effect, this even larger $16 \%$ difference between lists versus sentences receives no satisfactory explanation in Altarriba and Soltano. Their suggestion that the differing effect of semantic repetition for lists versus sentences reflects an effect of memory load is almost certainly incorrect: Park and Kanwisher (1994) carried out a parametric study of the effects of memory load, defined as the total number of to-be-remembered items in a list, and found that RB did not vary in degree as a function of systematically increasing memory load.

Altarriba and Soltano's (1996) attempt "to remedy the situation" by focusing on the list data (Experiment 2) rather than the sentence data (Experiment lB) is also problematic. First, a strong case can be made that sentence data are more fundamental (and hazardous to ignore) than list data: Everyday use of words involves sentences much more frequently than lists, and the human mind has evolved to process words in sentences rather than lists (see MacKay, in press). Second, list-sentence differences are at the core of important theories of memory, such as Gathercole and Baddeley's (1993, pp. 4-17) claim that two distinct and separate memory subsystems process and store sentences versus word lists: the phonological loop for lists versus the central executive for sentences. Altarriba and Soltano's list-sentence difference may therefore carry important implications for theories of memory, and should not be dismissed lightly.

Moreover, it is important to note that differences in repetition deficits within sentences versus lists pose problems for token individuation theory. Tokenization is a hypothetical process that applies in the same way regardless of whether a repeated word is part of a list or a sentence, and this context independence assumption has benefited token individuation theory in the past. Until recently, virtually no differences between RB in lists versus sentences have been reported. However, the results of Altarriba and Soltano (1996) and several other recent studies (e.g., MacKay \& Abrams, 1994; MacKay \& Miller, in press; Miller \& MacKay, 1994) indicate that repetition deficits can differ in nature and size for sentences versus lists, and these differences are difficult to explain within token individuation theory. To summarize, list-sentence differences and cross-language facilitation at rapid presentation rates are potentially important phenomena be- cause of the theoretical problems they pose, both for theories of repetition deficits and for more general theories of short-term memory.

\section{NONOCCURRENCE OF RELIABLE SB IN SPLIT-LANGUAGE SENTENCES}

The third surprising result in Altarriba and Soltano (1996) is the small (3\%) and nonsignificant SB effect in the split-language sentences of Experiment $1 \mathrm{~B}$, as compared with the much larger (9\%) SB effect in MacKay and Miller (1994). On the basis of their nonsignificant result, Altarriba and Soltano concluded that their data "contradict" and "fail to support" the results of MacKay and Miller, a conclusion that is flawed on several counts. First, without power analyses, no such conclusion is possible on the basis of nonsignificant results. Second, Altarriba and Soltano's Experiment 1B contained seven methodological problems (discussed below), and there is reason to believe that all seven factors pulled in the same direction, namely to diminish the SB effect (both absolutely and relative to RB) in their Experiment $1 \mathrm{~B}$. Because none of these design problems applied to MacKay and Miller, we conclude that Altarriba and Soltano's claim regarding contradiction is spurious and that their subsequent claim, "that conceptual relatedness alone is not sufficient to produce an RB effect" (p. 705) is open to question.

\section{Seven Methodological Problems in \\ Altarriba and Soltano (1996, Experiment 1B)}

1. Slower presentation rates: Repetition deficits occur only within a limited range of presentation rates, and in general, RB decreases in magnitude at slower rates (see, e.g., MacKay \& Miller, in press; MacKay, Miller, \& Schuster, 1994; Miller \& MacKay, in press). Because presentation rate was slower (133 msec/word) in Altarriba and Soltano (1996, Experiment 1B) than in MacKay and Miller (1994) - that is, $80 \mathrm{msec} /$ word on the average - the slower rate may have reduced the relative degree of SB in Altarriba and Soltano (Experiment 1B). Use of $117 \mathrm{msec} /$ word in Experiment 1A rather than $133 \mathrm{msec} /$ word may likewise have increased the relative degree of RB in Experiment $1 \mathrm{~A}$.

2. Longer lags: Repetition deficits are known to decrease in magnitude with lag (see, e.g., Kanwisher, 1987), defined as the number of words separating pretarget and target words (R1 and R2). Mean lag in MacKay and Miller (1994) was 1.31 words, versus 2.28 words in Altarriba and Soltano's (1996) Experiment 1B; the longer lags in Altarriba and Soltano may have reduced their relative magnitude of SB.

3. Use of an "unconditional" dependent measure: Altarriba and Soltano (1996) used simple target recall as their dependent measure in Experiment 1B, whereas MacKay and Miller (1994) used conditional target recall: A target (R2) was scored as correct if, and only if, its corresponding pretarget was correctly recalled. Conditional measures such as this are necessary in order to exclude trials where participants failed to detect the pretarget, an 
event that rules out the possibility of either SB or RB under any theory (see, e.g., MacKay et al., 1994; MacKay \& Miller, in press). Recent studies of RB and related phenomena such as the attentional blink have also adopted conditional measures for another reason, namely Kanwisher's (1991, Experiment 5) demonstration that facilitation rather than inhibition occurs when participants do not attend to, perceive, or recall the pretarget for a subsequently repeated target (for detailed discussion, see MacKay et al., 1994). Altarriba and Soltano's failure to compute conditional recall in Experiment $1 \mathrm{~B}$ is inconsistent with their use of a conditional measure in Experiment 2, and implies that their Experiment 1B data may include an indeterminate number of trials that would have offset or worked against observing a significant SB effect.

4. Relative lengths of targets and pretargets: Altarriba and Soltano (1996) did not equate relative length in letters of target and corresponding pretargets in Experiment 1B: $50 \%$ of the pretargets in their unrepeated target SB condition were longer than the corresponding targets, whereas $22 \%$ were shorter, and only $28 \%$ were of equal length. This pattern in their stimuli is important because our extensive pilot testing of the SB and RB paradigms indicated that recall of unrepeated targets varied as a function of the relative lengths of target and pretarget words: $58 \%$ recall when pretargets were longer than targets versus $83 \%$ recall when pretargets were shorter than targets. Because reduced recall of unrepeated targets will reduce $\mathrm{SB}$ (percent recall for unrepeated minus repeated targets), the pattern of relative lengths for targets and pretargets in the Altarriba and Soltano (Experiment 1B) stimuli points again toward artifactually reduced SB.

5. Salience of repeated targets: The materials in Altarriba and Soltano (1996, Experiment 1B) can be described as split-language sentences: One and only one language switch occurred per sentence, with the first phrase or part of the sentence in one language, and the remaining part in the other language. Moreover, pretargets and targets in their materials were always in different languages, increasing the salience of translation equivalents in the repeated target condition, and thereby reducing SB. In contrast, MacKay and Miller's (1994) materials consisted of mixed-language sentences, where most of the words appeared in one language, but a variable number of words appeared in the other language, as in, say, "Mike aprendió to drive a car and began manejar to work" (translation: "Mike learned to drive a car and began to drive to work."). This mixed-language procedure is essential in attempting to equate the salience of the target (and its relation to the pretarget) in RB and SB sentences containing repeated versus unrepeated targets.

6. A confound between language-switching, $S B$, and $R B$ : Because Altarriba and Soltano's (1996) sentences were always split-language for their SB experiment (1B), but were always same-language for their $R B$ experiment ( $1 A$ ), it is not appropriate to compare the degree of SB versus RB across these experiments because language switching is confounded with SB materials, and nonswitching is confounded with RB materials. Comparing the degree of
SB versus $R B$ requires procedures similar to those of MacKay and Miller (1994), where RB sentences (with exact repetitions) and SB sentences (with translation equivalents) both contained language switches.

7. Predictability of the language switch: Because the split-language sentences of Altarriba and Soltano (1996) usually contained two phrases or clauses, with the first clause of a sentence in one language, and the second clause in the other language, participants may have developed expectations as to where the language switch would occur in their materials. Because of the close association between the target words (R2) and the locus of the language switches in the Altarriba and Soltano materials, these expectations may have reduced SB in their Experiment 1B data. This problem does not apply to MacKay and Miller (1994) because language switches occurred at various syntactic locations, even within a single mixed-language sentence.

In summary, at least seven factors are likely to have reduced the SB effect in Altarriba and Soltano's (1996) Experiment 1B, and because four of these factors are known on empirical grounds to diminish the magnitude of repetition deficits, we conclude that Altarriba and Soltano's data neither contradict nor fail to support MacKay and Miller's (1994) demonstration of SB in mixedlanguage sentences. All seven factors also call into question Altarriba and Soltano's conclusion (insofar as it applies to sentences) "that conceptual relatedness alone is not sufficient to produce an RB effect" (p. 705).

We turn now to two additional differences that Altarriba and Soltano (1996) noted, but that are almost certainly irrelevant to the issue of why the SB effect was so small in Experiment 1B compared with that found by MacKay and Miller (1994). One is Altarriba and Soltano's observation that some of MacKay and Miller's (1992) sentences exhibited nonstandard word order or usage. The reason for this is that MacKay and Miller took care to equate the conceptual content of the screens and the number of screens per sentence across the eight versions of their mixed-language sentences. This control procedure meant that a Spanish translation equivalent sometimes had to be inserted into an English syntactic frame, or vice versa. However, this factor did not distinguish sentences containing repeated versus unrepeated SB targets in MacKay and Miller (1994), and so could not have differentially affected their observed degree of SB (i.e., the difference in recall of conceptually repeated vs. unrepeated targets). Nor can nonstandard usage be considered generally unrepresentative of language processing under RB conditions: Even with standard, single-language sentences, participants who experience RB are usually reporting an ungrammatical sentence (see, e.g., Kanwisher, 1987).

Second, Altarriba and Soltano (1996) noted that a single frame or RSVP screen in MacKay and Miller (1994) sometimes contained a phrase (e.g., as well) rather than a single word (e.g., también) as in their study, as if the phrase procedure might have amplified the degree of SB in MacKay and Miller (1994). Contrary to this sugges- 
tion, however, Abrams, Dyer, and MacKay (1996) found that $\mathrm{RB}$ decreases rather than increases in magnitude when phrases appear within the same screen rather than word by word or broken up as in standard RSVP. In short, MacKay and Miller (1994) used appropriately controlled and conservative procedures for comparing the degree of $\mathrm{SB}$ and $\mathrm{RB}$ in their mixed-language sentences.

\section{AN EXPLANATION OF CROSS-LANGUAGE FACILITATION AND THE LIST-SENTENCE EFFECT}

As Caplan and Waters (1990) pointed out, list-sentence differences cannot automatically be attributed to the differing processing characteristics of the separate and distinct stores for lists versus sentences postulated in multistore accounts of memory (e.g., Gathercole \& Baddeley, 1993, pp. 4-17). For example, recent studies have demonstrated a wide range of effects where language variables such as prosody, word frequency, syntax, and semantics influence immediate memory for lists (see, e.g., MacKay \& Abrams, 1994; MacKay \& Miller, in press; for reviews of earlier work, see Caplan \& Waters, 1990; Saffran, 1990). These effects pose challenges for the multistore approach because they would not be expected if processing and storing word lists involved a special memory system that is distinct and separate from the memory system for processing and storing sentences. Inconsistent effects likewise pose problems for the multistore approach, and the fact that RB occurred for lists and sentences, whereas semantic facilitation occurred for lists but not sentences in Altarriba and Soltano (1996), illustrates such an inconsistency.

We therefore examined Altarriba and Soltano's (1996) unexplained effects within a quite different theoretical framework known as the "distributed memory" approach (MacKay, in press). Under this approach, short-term memory is not an isolable system consisting of distinct and separate subsystems (e.g., for sentences vs. lists), but instead represents "an umbrella term for a heterogeneous array [of] capacities for temporary storage ... distributed over diverse cognitive subsystems" (Monsell, 1984, p. 328). One theory within the general distributed memory approach is node structure theory (NST; MacKay, 1987, 1990), where the mechanisms for storing and retrieving verbal materials in lists are inseparable from the mechanisms that have evolved for producing, comprehending, and representing language (see MacKay, in press).

MacKay and Bowman (1969) carried out the basic empirical groundwork for explaining Altarriba and Soltano's (1996) list-sentence difference within NST. They noted that common open class words such as drive (from Altarriba \& Soltano, Appendix C) usually have only a single meaning in sentences, but have many distinct meanings when they occur as isolated or unrelated words in lists. For example, the word drive, taken in isolation, has over 26 distinct meanings (even in pocket reference dictio- naries such as Dubois-Charlier et al., 1987), and each of these meanings has one or more distinct translation equivalents in Spanish, for example, nouns such as campaña, vigor, and incentivo meaning "campaign," "personal energy," and "incentive"; and verbs such as manejar, empujar, llevar, and obligar meaning "to drive a car," "to push," "to transport [passengers]," and "to compel." However, drive allows only a single meaning and only a single translation equivalent (manejar) in the context of a sentence such as "Mike learned to drive a car and began to drive to work." On the basis of such observations, MacKay and Bowman demonstrated that proficient bilinguals exhibit a semantic-level practice effect for translation equivalents in sentences, but not for identical translation equivalents in lists of unrelated words. When the bilinguals read a sentence in one language 12 times at maximum rate with $20 \mathrm{sec}$ between repetitions, the time to produce the sentences decreased as a logarithmic function of practice (see MacKay, 1982), and the time to produce wordfor-word translations of the sentences in their other language on the next four trials (13-16) showed perfect transfer. Speed-up in maximum rate for the word-for-word translations was $17 \%$, and was equivalent to 16 practice trials rather than 4 , a transfer effect entirely attributable to semantic-level processes. However, with exactly the same procedures for the same sentences scrambled into lists of unrelated words, transfer for the word-for-word translations was $-1 \%$ and nonsignificant.

How does NST represent the multiple meanings and phonological forms for words in lists processed by proficient Spanish-English bilinguals? Each distinct meaning of a word such as drive has a separate lexical node in NST, and for proficient Spanish-English bilinguals, a single lexical node represents concepts that are identical in Spanish and English. For example, drive has four distinct meanings corresponding to the Spanish translation equivalents manejar, vigor, empujar, and llevar, and a single lexical node represents each of these meanings. These four shared (Spanish-English) lexical nodes are shown in Figure 1 (in rectangles), together with the phonological representations for drive, manejar, vigor, empujar, and llevar (in rounded rectangles). As can be seen there, the phonological representation for drive connects bottom-up with all four lexical nodes, which in turn connect top-down with phonological representations corresponding to manejar, vigor, empujar, and llevar.

Under NST, three distinct processes underlie the comprehension and production of words: priming, node activation, and self-inhibition (see MacKay, 1990, for further details). Priming prepares a node for possible activation under a "most-primed-wins" principle, but otherwise resembles spreading activation (active nodes automatically prime all connected nodes in parallel, in proportion to their own degree of activity, and in proportion to the number of intervening connections). Node activation is necessary for the perception, comprehension, and production of words, and unlike priming, requires a special activating mechanism that operates sequentially rather 


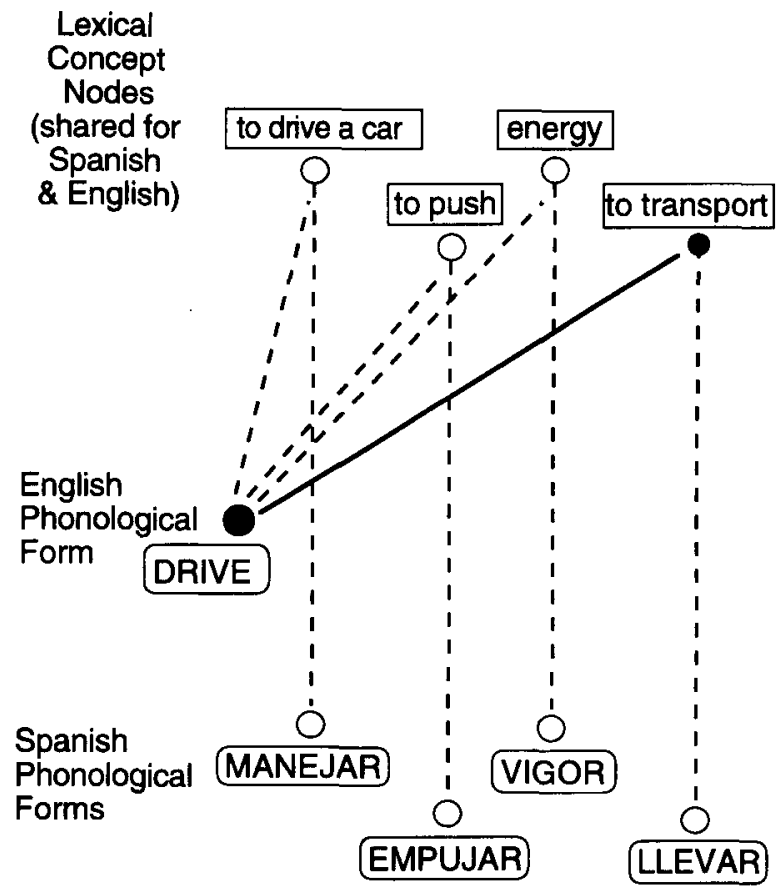

Figure 1. Connections in node structure theory between the phonological form for drive, a sample of its (shared SpanishEnglish) lexical concept nodes, and phonological forms for corresponding Spanish words. Initial presentation of drive primes without activating the unfilled nodes connected with broken lines (see MacKay, 1990, for the priming-activation distinction), but fully activates the nodes connected with solid lines, resulting in self-inhibition (solid node).

than in parallel. Self-inhibition is a brief inhibitory process that normally serves to terminate node activation (but not priming) after a set period of time.

What are the theoretical consequences of such connections and processes for understanding how bilinguals in Altarriba and Soltano (1996, Experiment 2) might process rapidly presented word lists such as drive zapatos drive, and drive zapatos manejar? One consequence is that initial presentation of drive in such lists would prime and activate the phonological nodes for drive, which would strongly prime the lexical nodes for all four meanings of drive in Figure 1, and activate the most primed one, such as the one meaning "to transport" (llevar). As a result, phonological nodes for drive and the lexical node for to transport may be undergoing self-inhibition (represented via solid nodes in Figure 1) at the time when the third word in the list appears. Thus, if the third word is drive, RB is a likely outcome because the self-inhibited phonological nodes for drive will be harder to activate than when the initial word is phonologically, orthographically, and semantically unrelated to drive.

A second consequence of node structures resembling Figure 1 is that initial presentation of drive will weakly prime the phonological representations for the full set of Spanish words that share lexical nodes with drive, including those for manejar, empujar, vigor, and llevar. As a result, if the third word in the list is manejar, seman- tic facilitation will occur; that is, phonological and lexical nodes for manejar will already be primed, and will thus be easier than normal to activate. Therefore, participants will more readily report manejar as part of this list than when the initial word is semantically unrelated to drive (consistent with Altarriba and Soltano's, 1996, findings).

Turning to the list-sentence effect, how would processing of drive differ for a list as opposed to a mixedlanguage sentence such as, "Mike aprendió to drive a car and began manejar to work" (translation: "Mike learned to drive a car and began to drive to work.")? As MacKay and Bowman (1969) noted, drive is likely to have only a single meaning and to allow only a single translation equivalent in the context of such a sentence. Thus, when a proficient bilingual encounters manejar in this sentence, the shared lexical node for drive and manejar will have been activated when the bilingual comprehends drive, and will be undergoing self-inhibition. This self-inhibition process (see MacKay, 1990, for further details) will make manejar more difficult than normal to encode under the time pressure of RSVP, so that immediate recall of manejar will be less likely than for a sentence with a semantically unrelated pretarget, for example, steer in "Mike aprendió to steer a car and began manejar to work." Now, with either drive or steer as pretargets, phonological nodes for manejar will not be undergoing self-inhibition, so that the inhibitory (SB) effect (i.e., the difference in target recall for unrepeated minus repeated targets) should not be as great as the RB effect in "Mike learned to drive a car and began to drive to work," where lexical and phonological nodes for drive are undergoing selfinhibition. However, reliable SB should nevertheless occur, as observed in MacKay and Miller (1994).

\section{FURTHER MISUNDERSTANDINGS}

On the basis of the preceding theoretical points, we can now address some further misunderstandings in how Altarriba and Soltano (1996) described MacKay and Miller (1994). One is that MacKay and Miller attributed Kanwisher and Potter's (1990) failure to find SB for within-language synonyms, for example, house and home, to small meaning differences in reference or connotation of house versus home. This claim is inaccurate: MacKay and Miller were making a much more detailed and general theoretical point, namely that, unlike cross-language translation equivalents such as house and casa, withinlanguage synonyms such as house and home have distinct or unshared lexical nodes in NST. Under NST, each word for which a meaning is known has at least one lexical node, representing a distinctive concept within the conceptual system for language. Lexical nodes in turn connect with phrase and proposition nodes within the language system, with connotative representations within an emotional system, and in the case of imageable words, with visuospatial representations within a referential system.

The fact that house and home have distinct lexical nodes allows these words to acquire differing (but language- 
universal) connotative associations over the course of a lifetime, by the simple process of forming different associative links to their differing lexical nodes. However, lacking shared lexical and phonological nodes, withinlanguage synonyms are immune to repetition deficits at the lexical and phonological levels under NST, and no one has argued for the existence of repetition deficits at referential or connotative levels. Nonetheless, within-language synonyms may connect with some of the same phrases and via these phrases to identical referential representations. For example, readers of a newspaper ad "house for sale" will acquire the same referential representation as for the ad "home for sale," despite the connotative differences between house and home. Similarly, referents for the phrases casa en Mexico and house in Mexico are identical but both phrases may differ referentially from casa en America and house in America. In short, the concepts "small meaning differences" and more generally "similarity in meaning" are much more complex than Altarriba and Soltano have suggested.

A second misunderstanding concerns the role of semantic factors in RB. MacKay and Miller (1994) argued for the existence of two theoretically distinct types of $R B$. If the two types are labeled $R B 1$ and $R B 2, R B 1$ can be considered a type of surface blindness that (1) occurs in word lists (e.g., Altarriba \& Soltano, 1996, Experiment 2); (2) is strongly influenced by orthographic and phonological factors; (3) involves existing nodes with old or highly practiced connections such as those illustrated in Figure 1; and (4) reflects the theoretical process of selfinhibition discussed above (see also MacKay, 1990, and 1987, pp. 146-187).

RB2, on the other hand, is a type of deep blindness: It underlies SB, as demonstrated in MacKay and Miller (1994). It is mainly confined to sentence processing, and it is linked to the process of forming new connections between words and phrases in sentences, rather than to a purely inhibitory process, a refractory period effect, or perceptual fusion of repeated words (see MacKay et al., 1994; MacKay \& Miller, in press). ${ }^{2}$ RB2 is also strongly influenced by semantic and syntactic factors, a postulate that other, recently reported, findings firmly support. One is the demonstration of MacKay and Abrams (1994) that RB increases in magnitude when repeated words occur in familiar phrases such as good night and night gown rather than in lists of unrelated words. Because phrases are fundamentally syntactic/semantic entities, this finding is consistent with a role for semantic and syntactic factors in the RB paradigm, and supports the existence of SB. Results of Abrams et al. (1996) suggest a similar conclusion: Abrams et al. presented RSVP screens that were either phrase incongruent; that is, contained nonphrases as in [They wanted to][play sports but] [ sports were not $][$ allowed], or were phrase congruent; that is, contained a single complete phrase or syntactic constituent, as in [They wanted] [to play sports][but sports][were not allowed]. Abrams et al. observed a significant increase in RB when RSVP screens were phrase incongruent rather than phrase congruent. This effect can be explained only if syntactic and semantic factors influence $R B$, as in the NST account of RB2, where RB can decrease or increase in magnitude depending on whether the RSVP procedure makes it easier or more difficult to form word-to-phrase links. An analogous effect has recently been reported for repetition deafness (MacKay \& Miller, in press; Miller \& MacKay, in press) and is likewise consistent with the existence of SB, with effects of semantic and syntactic factors on repetition deficits, and with the distributed memory approach to the relation between language and memory (see MacKay, in press).

\section{REFERENCES}

Abrams, L., Dyer, J. R., \& MacKay, D. G. (1996). Repetition blindness interacts with syntactic grouping in rapidly presented sentences. Psychological Science, 7, 100-104.

Altarriba, J., \& Soltano, E. G. (1996). Repetition blindness and bilingual memory: Token individuation for translation equivalents. Memory \& Cognition, 24, 700-711

BAVELIER, D. (1994). Repetition blindness between visually different items: The case of pictures and words. Cognition, 51, 199-236.

CaPlan, D., \& WATERS, G. S. (1990). Short-term memory and language comprehension: A critical review of the psychological literature. In G. Vallar \& T. Shallice (Eds.), Neuropsychological impairments of short-term memory (pp. 337-389). Cambridge: Cambridge University Press.

Dubois-Charlier, F., Pritchard, D. R., Senerth, D. T., \& Sola, J. M. (1987). The American Heritage Larousse Spanish dictionary: English/Spanish (1st ed.). Boston: Houghton Mifflin.

Gathercole, S. E., \& Baddeley, A. D. (1993). Working memory and language. Hillsdale, $\mathrm{NJ}$ : Erlbaum.

KANWISHER, N. G. (1987). Repetition blindness: Type recognition without token individuation. Cognition, 27, 117-143.

KANWISHER, N. G. (1991). Repetition blindness and illusory conjunctions: Errors in binding visual types with visual tokens. Journal of Experimental Psychology: Human Perception \& Performance, 17, 404-421.

Kanwisher, N. G., \& Potter, M. (1990). Repetition blindness: Levels of processing. Journal of Experimental Psychology: Human Perception \& Performance, 16, 30-47.

MaCKAY, D. G. (1982). The problems of flexibility, fluency, and speed-accuracy trade-off in skilled behavior. Psychological Review, 89, 483-506.

MACKAY, D. G. (1987). The organization of perception and action: $A$ theory for language and other cognitive skills. New York: SpringerVerlag.

MACKAY, D. G. (1990). Perception, action, and awareness: A three body problem. In W. Prinz \& O. Neumann (Eds.), Relationships between perception and action (pp. 269-303). Berlin: Springer-Verlag.

MACKAY, D. G. (in press). The stages of processing metatheory and the relation between perception, action, and memory. In W. Bechtel \& G. Graham (Eds.), A companion to cognitive science. Oxford: Blackwell.

MaCKAY, D. G., \& ABrams, L. (1994, November). Chunking and repetition deficits challenge capacity theories and the single attachment principle. Paper presented at the 35 th annual meeting of the Psychonomic Society, St. Louis.

MacKay, D. G., \& Bowman, R. W. (1969). On producing the meaning in sentences. American Journal of Psychology, 82, 23-39

MacKay, D. G., \& Miller, M. D. (1992). Semantic blindness: Repetition suppression at the semantic level. Unpublished manuscript, University of California, Los Angeles.

MaCKay, D. G., \& Miller, M. D. (1994). Semantic blindness: Rapidly presented repeated concepts are difficult to encode and recall. Psychological Science, 5, 52-55.

MaCKay, D. G., \& Miller, M. D. (in press). Can cognitive aging con- 
tribute to fundamental psychological theory? Repetition deafness as a test case. Aging, Cognition \& Neuropsychology.

MacKay, D. G., Miller, M. D., \& Schuster, S. P. (1994). Repetition blindness and aging: Evidence for a binding deficit involving a single, theoretically-specified connection. Psychology \& Aging, 9, 251-258.

Miller, M. D., \& MacKay, D. G. (1994). Repetition deafness: Repeated words in computer compressed speech are difficult to encode and recall. Psychological Science, 5, 47-51.

MiLLER, M. D., \& MACKAY, D. G. (in press). Relations between language and memory: The case of repetition deafness. Psychological Science.

MONSELL, S. (1984). Components of working memory underlying verbal skills: A "distributed capacities" view. In H. Bouma \& D. G. Bouhuis (Eds.), Attention and performance $X$ : Control of language processes (pp. 327-350). Hove, U.K.: Erlbaum.

Park, J., \& Kanwisher, N. (1994). Determinants of repetition blindness. Journal of Experimental Psychology: Human Perception \& Performance, 20, 500-519.

SAFFran, E. M. (1990). Short-term memory impairment and language processing. In A. Caramazza (Ed.), Cognitive neuropsychology and neurolinguistics: Advances in models of cognitive function and impairment (pp. 137-168). Hillsdale, NJ: Erlbaum.

SHIFFRIN, R. M., \& NosofSKY, R. M. (1994). Seven plus or minus two: A commentary on capacity limitations. Psychological Review, 101 357-361.
ZHANG, G., \& Simon, H. A. (1985). STM capacity for Chinese words and idioms: Chunking and acoustical loop hypotheses. Memory \& Cognition, 13, 193-201.

\section{NOTES}

1. This example was taken from Altarriba and Soltano (1996, Appendix $\mathrm{C}$ ), and illustrates two general and interrelated problems associated with their list materials that we will discuss in detail later. One concerns ambiguity: "Unrelated" pairs such as steer-drive are not entirely unrelated unless participants interpreted steer to mean a type of animal. The other is that some of their "unrelated" cross-language pairs (e.g., guiar-drive) were actually translation equivalents: Dictionaries (e.g., Dubois-Charlier, Pritchard, Senerth, \& Sola, 1987) list both guiar and manejar as translation equivalents of drive.

2 . The self-inhibition process that follows word activation plays a direct role in the process of forming new connections between words and phrases in node structure theory (see MacKay, 1990).

(Manuscript received February 16, 1996; revision accepted for publication April 28, 1996.) 